\title{
Initial Experience with Simple Oncoplastic Breast Conserving Surgery in Nepal: A Case Report
}

\author{
Yogendra P Singh', Suman Khanal ${ }^{2}$ \\ 1Department of Surgery, Maharajgunj Medical Campus, Tribhuvan University Teaching Hospital, Institute of \\ Medicine, Maharajgunj, Kathmandu, Nepal 'Department of Surgical Oncology, Gastroenterology, BP Koirala \\ Memorial Cancer Hospital, Bharatpur, Nepal
}

\section{Corresponding author:}

\section{Yogendra P Singh, MD, PhD}

Department of Surgery, Maharajgunj Medical Campus, Tribhuvan University Teaching Hospital, Institute of Medicine, Maharajgunj, Kathmandu, Nepal

Email: ypsingh2065@gmail.com

Submitted : Jun 28, 2020

Accepted : July 31, 2020

\begin{abstract}
Oncoplastic breast conserving surgery is increasingly used in the management of early breast cancer. Though its use in Nepal is increasing, it is still under-utilized. We present a case of upper outer quadrant early breast cancer located away from nipple-areola complex managed with radial ellipse segmentectomy 10 years back and under regular follow up. We recommend its usage in upper outer quadrant lesions because of its simplicity, access for sentinel lymph node biopsy and good cosmetic outcome.
\end{abstract}

Keywords: Early breast cancer, lumpectomy, simple oncoplastic surgery

\section{INTRODUCTION}

T he word 'oncoplastic' is derived from two Greek words 'onco' (tumor) and 'plastic' (to mould). ${ }^{1}$ It entails the use of plastic techniques to reshape/mould the remaining breast after excision of breast cancer. It allows wider excision expanding the limits of breast conservation while preventing the cosmetic deformities of the breast. Due to these benefits, use of oncoplastic breast conserving surgeries (BCS) is increasing. ${ }^{2}$ It has been practiced widely as a standard of care for early breast cancer even in low-income countries ${ }^{3,4}$ despite some limitations. Level I simple oncoplastic BCS includes removal of a moderate amount of breast tissue (about 20-25\%) and the post lumpectomy space is filled with local glandular advancement (volume displacement). ${ }^{5}$ We report a case of early breast cancer managed 10 years back in the early days with radial ellipse segmentectomy oncoplastic technique.

\section{CASE PRESENTATION}

A 29-year-old multiparous, premenopausal TibetoBurman lady presented with a painless right breast lump for ten days. The lump was not associated with nipple discharge. She had menarche at the age of 13 years. There was no history of oral contraceptive pills use. Family and past medical history were not significant. Local examination of the right breast revealed a hard and non-tender lump of $1.5 \times 1.5 \mathrm{~cm}$ over upper outer quadrant. The lump was mobile and not fixed with underlying chest wall or overlying skin. Bilateral axilla and left breast were normal.

Ultrasonography of the right breast showed a 16X14 
$\mathrm{mm}$ sized hypoechoic lesion with irregular margins in upper outer quadrant at 10 o'clock position. The lesion had minimal internal vascularity suggestive of malignancy. Bilateral axilla and left breast findings were normal. Fine needle aspiration cytology revealed malignant lesion. Metastatic work up in the form of chest X-ray, abdominal ultrasound, liver function tests were normal. She decided to undergo oncoplastic breast conserving surgery.

Surgical procedure: Under general anesthesia, diluted methylene blue $(1 \mathrm{ml}$ methylene blue +4 $\mathrm{ml}$ normal saline) was injected all around the tumor with $1 \mathrm{~cm}$ margin to delineate the line of dissection (Fig. 1). A radial ellipse skin incision was given over central part of the lesion. Both upper and lower skin flaps were raised. An elliptical incision was given over blue stained margin of glandular tissue with addition of $0.5 \mathrm{~cm}$ on both inferomedial and superolateral side (non-stained breast tissue). Lumpectomy was done and the specimen labeled as long thread indicating lateral and short thread indicating superior margin (Fig. 2). Sentinel lymph node biopsy was done via the same incision. Two lymph nodes were retrieved; one was blue stained. Both edges of the glandular breast tissue were approximated with polyglactin 3:0 interrupted suture. Skin was closed with subcuticular 4:0 polyglactin.

Postoperative period was uneventful. The patient was discharged on third postoperative day. Histopathological examination showed a grade II invasive ductal carcinoma with lymphovascular invasion. Both lymph nodes were negative for tumor cells. Both estrogen and progesterone receptors were negative. She received six cycles of anthracycline based chemotherapy and total 40 Gray of external beam radiotherapy (2 Gray fraction x 5 days a week). According to Harvard Scale, ${ }^{6}$ her cosmetic outcome at six months post operatively was excellent. Even after 10 years of surgery, she is well satisfied with the cure from the disease and the cosmetic outcome (Fig. 3).

\section{DISCUSSION}

Oncoplastic BCS techniques are being used more frequently in the management of early breast cancer. ${ }^{2}$ These techniques can be level I or level II. ${ }^{7}$ Selection of particular technique depends on breast size, shape, degree of ptosis, tumor location and tumor-to-breast volume ratio., 8,9 Level I techniques are easier allowing for resection of up to $20 \%$ of breast volume. ${ }^{10}$ There are various techniques for removal of lesions in upper outer quadrant like donut mastopexy, radial ellipse segmentectomy or lateral mammoplasty. ${ }^{11,12}$ We used radial segmentectomy in our case to remove lesion in the upper outer quadrant, in early days when oncoplasty was still in its infancy in Nepal.

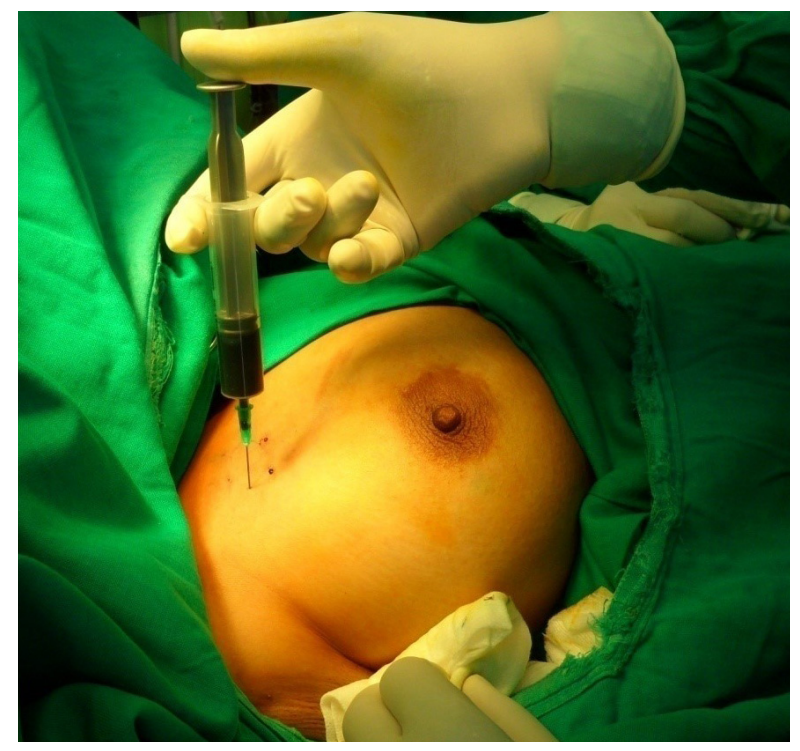

Fig 1. Injection of methylene blue dye around tumor in right upper outer quadrant of breast $1 \mathrm{~cm}$ away from the tumor

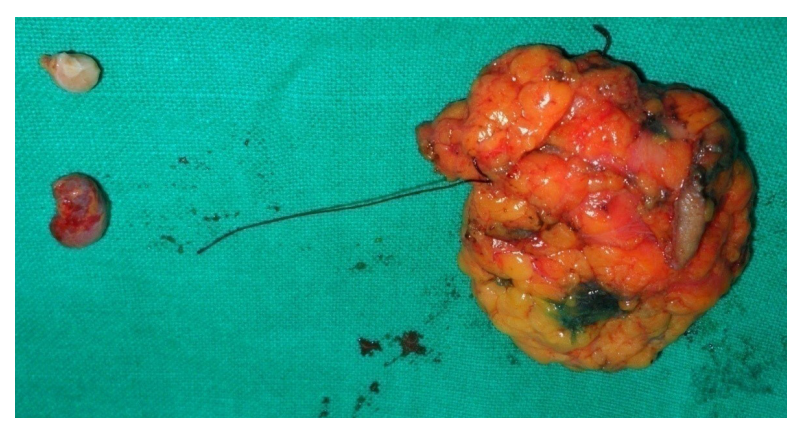

Fig 2. Post lumpectomy specimen $(4 \times 5 \mathrm{~cm})$ with one blue stained sentinel lymph node. Short thread superior margin, long thread - lateral margin and a thin rim of skin)

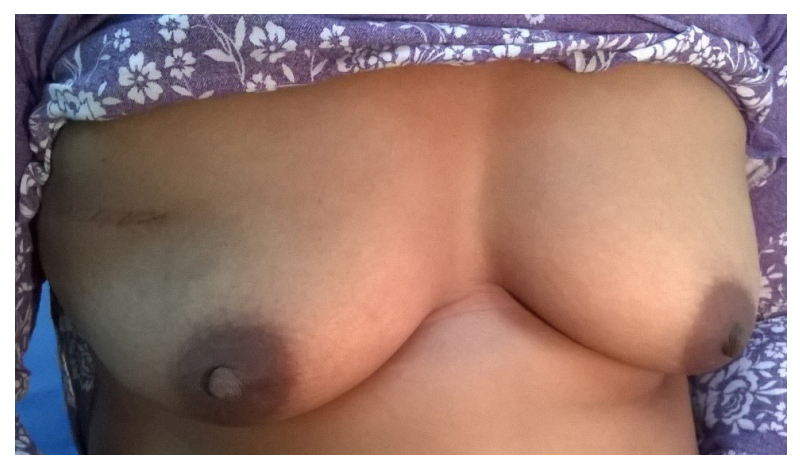

Fig 3. Ten years follow-up with excellent cosmetic outcome

Radial ellipse segmentectomy is a level I technique that can be applied on any quadrant to remove the tumor. ${ }^{13}$ In our case, though the lesion could have been removed via periareolar or circumareolar incision as recommended in superior region of breast, $^{11}$ we chose the radial incision for two 
reasons: (a) the lesion was in upper outer quadrant away from NAC (nipple-areola complex) so the scar would be hidden from cleavage area, (b) accessibility of axilla for sentinel lymph node biopsy from the same incision. The radial ellipse incision in original description ${ }^{13}$ was close to nipple, however our incision was much farther away from NAC. The cosmetic outcome of radial segmentectomy is said to be intermediate between that of donut mastopexy and lateral mammoplasty ${ }^{12}$ for upper outer quadrant lesions. However, the cosmetic outcome in our case was excellent.

The advantages of radial segmentectomy are its simplicity, and applicability in lesions anywhere in the breast. But it is preferably avoided in resection of upper inner quadrant lesions due to visible scar in the cleavage area. The adjunct use of frozen section during oncoplastic resection is recommended for two reasons: (a) by assuring margin negativity, it avoids the risk of re-excision that might compromise aesthetic outcome and increase breast asymmetry (b) lowers risk of oncologic failure. ${ }^{13}$ However we did not use frozen section in our case due to technical limitations.

Use of oncoplastic breast conserving surgeries is minimal in Nepal. Data from a prominent tertiary care cancer hospital in Nepal in the year 2018 showed none to be an oncoplastic surgery. ${ }^{14}$ Despite being equivalent in outcome compared with mastectomy, this lower uptake of oncoplastic techniques including radial segmentectomy could possibly be due to limited access to radiotherapy, patient preference and surgeon's judgement. ${ }^{17}$

The standard approach for early stage breast cancer is breast conserving surgery including use of oncoplastic techniques for resections more than $10 \%$, followed by radiation. ${ }^{10,15,16}$ So we need to apply more of these techniques in clinical practice. Given the simplicity, good cosmetic outcome and easy access to axilla for upper outer quadrant lesions away from NAC, the radial ellipse segmentectomy seems an attractive technique which can even be done by general surgeon with a short training.

\section{CONCLUSION}

Radial ellipse segmentectomy is a simple, easy level I oncoplastic technique suitable for upper outer quadrant lesions away from NAC with good cosmetic outcome.

\section{CONFLICT OF INTEREST}

None declared.

\section{CONSENT}

Consent has been obtained from the patient to publish this report and the images.

\section{REFERENCES}

1. Grotting JC. Plastic Surgery: Breast. Elsevier Health Sciences; 2012. 992 p.

2. Jonczyk MM, Jean J, Graham R, Chatterjee A. Surgical trends in breast cancer: a rise in novel operative treatment options over a 12 year analysis. Breast Cancer Res Treat. 2019 Jan;173(2):267-74.

3. Khanal S, Singh YP, Sharma R, Pandit K. Round Block Technique in Management of Breast Lesions. Kathmandu Univ Med J. 2019;67(3):248-50.

4. Khanal S, Singh YP, Sharma R. Batwing Technique in Large Volume Excision of Breast Lesions: Case Report. Journal of Institute of Medicine Nepal. 2019;41(2):70-72.

5. Patel K, Bloom J, Nardello S, Cohen S, Reiland J, Chatterjee A. An Oncoplastic Surgery Primer: Common Indications, Techniques, and Complications in Level 1 and 2 Volume Displacement Oncoplastic Surgery. Ann Surg Oncol. 2019 Oct;26(10):3063-70.

6. Harris JR, Levene MB, Svensson G, Hellman S. Analysis of cosmetic results following primary radiation therapy for stages I and II carcinoma of the breast. Int I Radiat Oncol Biol Phys. 1979 Feb;5(2):257-61.

7. Clough KB, Kaufman GJ, Nos C, Buccimazza I, Sarfati IM. Improving breast cancer surgery: a classification and quadrant per quadrant atlas for oncoplastic surgery. Ann Surg Oncol. 2010 May; 17(5):1375-91.

8. Weber WP, Soysal SD, Fulco I, Barandun M, Babst D, Kalbermatten $D$, et al. Standardization of oncoplastic breast conserving surgery. Eur J Surg Oncol. 2017 Jul;43(7):1236-43.

9. Kaviani A, Safavi A, Mohammadzadeh N, Jamei K, AnsariDamavandi M, Salmon RJ. Oncoplastic surgery in breast conservation: a prospective evaluation of the patients, techniques, and oncologic outcomes. Am J Surg. 2014 Nov;208(5):727-34.

10. Dixon JM, Barber MD. Breast Surgery E-Book: Companion to Specialist Surgical Practice. 6th ed. Elsevier Health Sciences; 2018. $306 p$.

11. Rovere GQ della, Benson JR, Nava M, editors. Oncoplastic and Reconstructive Surgery of the Breast. 2 edition. New York: Informa Healthcare; 2010. 304 p.

12. Elahmady R, Ibrahem W, Magdy M. Evaluation of different oncoplastic procedures used in the treatment of early breast cancer located in the upper outer quadrant. Life Sci J [Internet]. Available from: http://www.lifesciencesite.com/lsj/ Isj161219/15_35804|sj161219_106_114.pdf

13. Holmes DR, Schooler W, Smith R. Oncoplastic Approaches to Breast Conservation [Internet]. Vol. 2011, International Journal of Breast Cancer. Hindawi; 2011 [cited 2020 Jul 26]. p. e303879. Available from: https://www.hindawi.com/journals/ijbc/2011/303879/

14. BPKMCH Annual Report - 2018 [Internet]. BP Koirala Memorial Cancer Hospital; 2019 [cited 2020 Aug 24]. Available from: https:// archive.org/details/bpkmch-annual-report-2018

15. Julien JP, Bijker N, Fentiman IS, Peterse JL, Delledonne V, Rouanet $P$, et al. Radiotherapy in breast-conserving treatment for ductal carcinoma in situ: first results of the EORTC randomised phase III trial 10853. EORTC Breast Cancer Cooperative Group and EORTC Radiotherapy Group. Lancet. 2000 Feb 12;355(9203):528-33.

16. Veronesi U, Cascinelli N, Mariani L, Greco M, Saccozzi R, Luini A, et al. Twenty-year follow-up of a randomized study comparing breastconserving surgery with radical mastectomy for early breast cancer. N Engl J Med. 2002 Oct 17;347(16):1227-32.

17. Locker GY, Sainsbury JR, Cuzick J, ATAC Trialists' Group. Breast surgery in the "Arimidex, Tamoxifen Alone or in Combination" (ATAC) trial: American women are more likely than women from the United Kingdom to undergo mastectomy. Cancer. 2004 Aug 15;101(4):735-40. 